\title{
Research on Fan Operation in the Entertainment Industry
}

\author{
Wenyi Shi \\ ${ }^{1}$ Faculty of Art Design, Beijing University of Technology, Beijing, 100124, China \\ *Corresponding author.Email:yoon530420412@163.com
}

\begin{abstract}
With the development of new technologies such as the Internet and the gradual diversification of fan needs, fan operations in the entertainment industry are facing higher requirements for professionalism, and some operational strategies urgently need to be more detailed. Therefore, this paper researches by sorting and analyzing numerous reports and documents, aiming to discover the advantageous strategies of fan operation of different enterprises in the entertainment industry, find out the problems faced in the operation process and propose reasonable solutions. In the end, it was discovered that a good fan operation strategy is always time-sensitive and requires constant insight into the changes in fan needs and adjustments. In addition, these companies also need to cooperate to help the development of the entire fan operation industry chain.
\end{abstract}

Keywords: Fan operation, Entertainment industry, Fan Economy

\section{INTRODUCTION}

As the fan culture has become more and more enriched, the importance of fans has increased and their loyalty has declined. At the same time, as the impact of the Internet on various industries has become deeper, the consumption patterns of fans have been continuously upgraded and the collective power of fans has become stronger. These changes in fan characteristics have significantly increased the difficulty for companies to operate fans, and some fan operation strategies need to be updated and upgraded urgently. The previous research has included a differentiated interpretation of the development model of the fan economy at different stages and the realization effect brought by the operating model in various fields [1], and has carried out an analysis of fan behavior based on an independent program such as Chuang 2021 [2]. It is not difficult to see that these studies have not focused on the entertainment industry and lack the analysis of the unique strategies of different types of enterprises in the fan operation link and the role it plays. Therefore, in this paper, the discussion will focus on the status quo of fan operation and development of artist agencies and video platforms. In addition, it will analyze the shortcomings of the fan's operation strategy based on the actual situation and put forward reasonable suggestions for improvement and a brief description of the possible impact.

\section{THE CURRENT DEFINITION OF FAN OPERATION AND THE FOUR OPERATING STAGES}

\subsection{The Current Definition of Fan Operation}

The scope of discussion in this article is defined in the entertainment industry, so the fan operation refers to the continuous emotional stimulation of fans with the help of some professional operation methods, strengthen fans' attention to artists, deepen fans' impression of artists, and fully integrate and mobilize fans to participate in the communication work[3]. The goal is to increase fan stickiness and achieve effective conversion of fan popularity.

The rapid development of the Internet in recent years has broken the limitations of time and space and has given new vitality to the fan economy. Different types of companies have developed unique network platforms to operate fans in a planned and organized manner. The operating model of the platform is to attract fans through clear points of interest, provide these users with diversified and personalized products and services, and ultimately transform them into consumption and achieve profitability. 


\subsection{Four Fan Operation Stages}

Fans are the mainstay of promoting the development of the fan economy, so fan operations have also played a significant role in maintaining the vigorous development of the fan economy. Fan operation can be divided into four stages_fan acquisition, fan conversion, fan retention and fan self-expansion[4].

Obtaining fans is the initial stage. The main goal of this stage for the company is to understand the points of interest of potential users, and create topics for artists based on these points of interest to attract these potential users and turn them into fans. This stage is very important, because it can expand the artist's fan base and lay a solid foundation for subsequent increase in popularity and influence.

Fan conversion is a stage that can reflect a significant increase in user stickiness. In this stage, the company focuses on increasing the emotional investment of fans to artists, to lead them to participate in some activities that help artists to enhance their commercial value. The time, energy and money that fans voluntarily contributed to this process have provided great support to the career development of the artist.

The main task of the fan retention stage for the company is to mobilize fans' enthusiasm for auxiliary promotion work through some welfare activities during the period when artists are not frequently promoted, to achieve the purpose of maintaining the number and quality of fans. Ensuring the stability of the number of fans and the activity level can allow brands who want to cooperate with artists to see the stable popularity of artists, which may promote the success of some commercial endorsements.

The self-expansion stage of fans fully demonstrates that the self-consciousness generated by fans based on the very deep emotional sustenance of artists is a powerful boost to the economic development of fans. In this process, fans take the initiative to recreate some existing materials and recommend them to non-fans to achieve the purpose of expanding the fan base. Although the main executors at this stage are fans, they also need the support of artist agencies, video platforms and other companies. The joint efforts of all stakeholders will maximize the benefits of the fan economy.

\section{ENTERPRISE'S FAN OPERATION METHODS AND ITS ROLE IN FAN ECONOMY}

The fan economy is a huge field, to operate it well, different types of enterprises in the entertainment industry need to give full play to their advantages at the appropriate stage. This means that they need to know what kind of contribution they can make to the development of the fan economy and some effective execution methods that comply with market rules. Next, WAJIJIWA and Tencent Video will be analyzed as typical cases of the artist agency and video platform.

\subsection{Artist Agency}

As the artist's most direct responsibility, the artist agency should have the most thorough understanding of the characteristics, development trends and reasonable operating models of the fan community. While tailoring the development plan for artists, it should also fully regards the orderly operation of fans as a key consideration.

Take WAJIJIWA Entertainment as an example, it has a very rich number of artists, and most of them are artist groups that have participated in talent shows and made successful debuts[5]. In the early days after the talent show, the fan community will create positive traffic entries for promotion based on the characteristics of the artists during the game. At this time, the company will pay attention to the requirements and expectations of the development of the artists put forward by the fans of different members in the entries, and will serve these keywords as important reference suggestions for the artist's future planning. This approach of meeting the needs of fans as much as possible will make fans feel that their ideas are valued by the company, and it is easy to improve the cooperation of fans in subsequent dockings with the company. After that, the company developed and implemented an online fan club. Fans need to pay a fixed monthly fee to get some membership benefits, such as viewing the artist's undisclosed pictures and videos, seeing the logs shared by the group members only on the platform and obtaining the qualifications for participating in offline events and the right to preferential purchase of tickets. Most of the fans attracted by the app are deep fans who are willing to invest a certain amount of emotion, time, and energy in the artist. From the perspective of the input-output ratio, fans will take the initiative to maintain their attention to the artist, thereby consolidating their artist's enthusiasm for supporting activities. In addition, issuing physical or digital albums and holding online and offline concerts from time to time can not only effectively increase the exposure of artists, but also show their earnest attitude towards their careers and their determination to repay fans with good works. These attractive activities not only enables fans to be more dedicated and active in supporting the artist's career, but also provide them with a wealth of materials and promote the quality of their re-creation and re-recommendation to become higher.

\subsection{Video Platform}

The video platform gradually transforms the artist's fans into its own loyal users through multi-field cooperation with the artist. In order to help artists to 
promote their works and maintaining fans, they also use the popularity of the artists to obtain some actual benefits.

Taking Tencent Video as an example, in recent years, it has built a celebrity spokesperson team composed of popular artists. The joint promotion of these people with different identities such as actors, singers, and idols means that the video platform can broaden its visibility in different fields and attract the attention of fans of artists[6]. After that, the video platform will buy out the exclusive rights to most of the artists' film and television works and variety shows, and at the end of the video trailer, it will be stated that the work will only be broadcast on this platform to remind fans to come to this site to contribute page views after the work is broadcast. In addition, if fans choose to join the membership, they can give wonderful videos to their friends to watch for free through WeChat, which may prompt some users who have a good impression of the artist to increase their love of the artist and then become fans. At the same time, if fans want a smoother experience of chasing dramas, they can also use their membership status for advanced on-demand broadcasting. Unlocking the following plot earlier than ordinary users means that they will discuss the work on social platforms first. These interesting insights may make other ordinary users curious about the new content, so they will recharge and become VIPs to get the advancement of watching these plots. This behavior attracted more paying users to the platform and also promoted an increase in daily active users. Finally, the most creative operating strategy is the establishment of Doki, which uses an interactive community model to open up a channel for fans to find people with similar interests and integrate into the star-chasing atmosphere together.

\section{PROBLEMS ENCOUNTERED BY ENTERPRISES IN OPERATING FANS AND REASONABLE IMPROVEMENT MEASURES}

\subsection{Problems Encountered By Artist Agency}

The artist agency encountered some problems while promoting the development of the fan economy. Firstly, the company's management of fan clubs is relatively tough. If fans want to apply to join again after quitting the fan club, they need to copy the corresponding membership rules. This operating rule is not respectful to fans, and it will especially make fans who temporarily suspend their membership due to personal reasons lose their enthusiasm to join the club again and even pay attention to artists. In response to this problem, the company should change its attitude towards fan groups that have been with artists for a long time. When the fans withdraw from the fan club, the company should use simple research to understand the reasons for their withdrawal and suggestions for improving the fan club without infringing on their privacy. When these fans choose to re-enter the fan club, the company should sincerely welcome their comeback and thank them for their dedication by sending email. The company should understand that taking good care of the emotions of old fans is the basis of fan operation and only after completing this task can it develop new fans without worries.

Secondly, the communication between the company and the fan groups of different members is relatively ineffective. After conflicts occurred between different fan groups and reported to the company, the company's approach was to force the fan groups to calm down by suspending the connection with the conflicting parties and canceling the two parties' participation in subsequent offline activities. This behavior of substituting prohibition for management is very irresponsible and will only intensify contradictions, causing fan groups to distrust the company and subsequently refuse to support the company's work. In order to avoid this unfavorable situation, the company should take the initiative to understand the specific reasons for the conflict and the demands of all parties after knowing that the fans have quarreled, and then analyze reasonable points of view and provide solutions as soon as possible to maintain the harmony of the fan circle. In addition, from a long-term perspective, the company should summarize the experience in handling this conflict and appropriately adjust its way of operating artists to make fans more satisfied. For example, the company does not make fixed constraints on the performance style of the combination, and based on respecting the ranking rules of the talent show, deliberately let the music works present a style suitable for different members in different periods of activity. This strategy is dedicated to allowing every member to be noticed at different times, which helps to encourage fans of different members in the portfolio to recognize the company's operating model for artists, thereby making the communication between fan representatives and the company more harmonious and smooth.

\subsection{Problems Encountered By Video Platform}

After many years of operation, the daily active user of Video's derivative platform is only prominent when there are welfare activities or offering the chance to vote for players on this application, while other times are relatively stable, and it has not achieved the goal of creating a closed-loop star chasing scene and assisting the overall platform to increase its activity for a long time. In order to solve this problem, the company should thoroughly analyze the existing derivative platform's design and publicity deficiencies. First of all, the derivative platform only exists inside the video platform, and the prompts for the operation method are neither 
eye-catching nor clear. Thus, this derivative platform cannot provide good guidance to people who are new to it. In response to this situation, the company should provide some introductions and tips on the main functions, operation methods, and welfare activities of the derivative platform at the top of the page after entering the operating interface, to help fans believe that they will use it for a long time to get better star-chasing experience at the early stage of using this platform. Secondly, the functions that the derivative platform has developed are relatively limited, which cannot meet the needs of fans for self-expanding on this platform. The company should regularly research fans' suggestions for improvements to the derivative platform through the message section of the platform and fully analyze these data , then upgrade and develop new sections according to dynamic changes in demand. At present, it is clear that the part that needs to be improved is to allow fans to re-create existing materials, add a section for displaying fan work in the derivative platform and allow sharing to external platforms, which will trigger more people to come to this platform to appreciate works, not only can enlarge fans Groups can also promote the use and popularity of this platform.

\section{CONCLUSIONS}

This paper studies the contributions of different companies in the entertainment industry to fan operation, as well as the problems encountered during the operation and reasonable improvement measures. In the end, it is concluded that the maintenance of the fan operation industry chain in the entertainment industry first requires different types of enterprises to fully understand the dynamic needs of fans, and appropriately adjust their fan operation strategies according to the changes in these opportunities. Secondly, it is also very necessary for all kinds of companies to give play to their advantages in the links they are good at, and to assist other companies in starting their work in other links. While striving to improve the business level of its own company, each company also has a sense of responsibility to help the entire fan operation industry chain to flourish. However, this paper only mainly analyzes two different types of enterprises, and the research on other enterprises is just a summary, lacking detailed analysis. If there are opportunities to continue research in the future, other types of companies such as social media and brands will be the main research objects, and the future research will also show their contributions to fan operations in detail and make feasible suggestions for them to overcome their shortcomings and find ways to improve.

\section{REFERENCES}

[1] Xiang Liang. (2021) Fan Economic Operation in the Era of Traffic. Times of Fortune, No.06, p. 21
[2] Qing Li, Aimin Zhu. (2021) Analysis of Fans' Behavior in Cultivation Programs from the Perspective of Interactive Ceremony Chain-Taking "Creation Camp 2021" as an example. Radio \& TV Journal, No.08, pp. 44-46

[3] JieMuYiXian. (2019) Four directions to analyze fan operations, this may be the most comprehensive strategy for fan circle insights. https://m.sohu.com/a/322469499_216932.

[4] CongGongZhongPu. (2020) The operating model of the fan economy. https://m.cifnews.com/article/72997?origin=baidu_ wenda.

[5] Zhuo Chen. (2019) WAJIJIWA: Digging into the idol economy. Investment and Cooperation, No.04, pp. $47-48$

[6] Na Yang. The study of the strategy that Tencent Video utilizes in its user adoption, retention, engagement, conversion and reflux. (2017) Wuhan University 